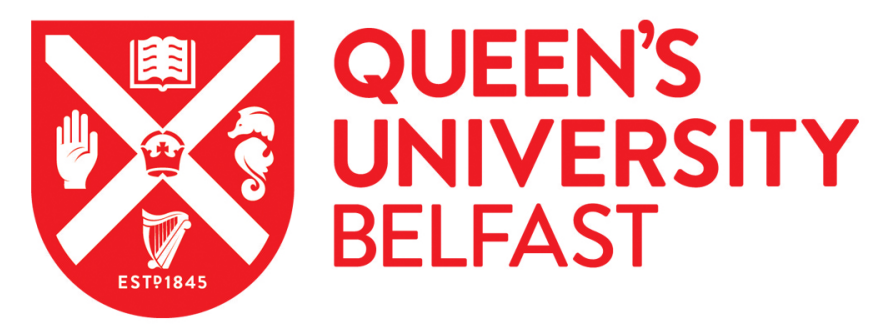

\title{
Numerical modelling of heat transfer in a cavity due to liquid jet impingement for liquid supported stretch blow moulding
}

Smyth, T., Menary, G., \& Geron, M. (2018). Numerical modelling of heat transfer in a cavity due to liquid jet impingement for liquid supported stretch blow moulding. In Proceedings of the 21st International ESAFORM Conference on Material Forming: ESAFORM 2018 (Vol. 1960). [090012] (AIP Conference Proceedings; Vol. 1960). American Institute of Physics Inc.. https://doi.org/10.1063/1.5034938

Published in:

Proceedings of the 21st International ESAFORM Conference on Material Forming: ESAFORM 2018

Document Version:

Publisher's PDF, also known as Version of record

Queen's University Belfast - Research Portal:

Link to publication record in Queen's University Belfast Research Portal

Publisher rights

(C) 2018 AIP Publishing LLC.

This work is made available online in accordance with the publisher's policies. Please refer to any applicable terms of use of the publisher.

\section{General rights}

Copyright for the publications made accessible via the Queen's University Belfast Research Portal is retained by the author(s) and / or other copyright owners and it is a condition of accessing these publications that users recognise and abide by the legal requirements associated with these rights.

Take down policy

The Research Portal is Queen's institutional repository that provides access to Queen's research output. Every effort has been made to ensure that content in the Research Portal does not infringe any person's rights, or applicable UK laws. If you discover content in the Research Portal that you believe breaches copyright or violates any law, please contact openaccess@qub.ac.uk. 
Numerical modelling of heat transfer in a cavity due to liquid jet impingement for liquid supported stretch blow moulding

Trevor Smyth, Gary Menary, and Marco Geron

Citation: AIP Conference Proceedings 1960, 090012 (2018); doi: 10.1063/1.5034938

View online: https://doi.org/10.1063/1.5034938

View Table of Contents: http://aip.scitation.org/toc/apc/1960/1

Published by the American Institute of Physics 


\title{
Numerical Modelling of Heat Transfer in a Cavity due to Liquid Jet Impingement for Liquid Supported Stretch Blow Moulding
}

\author{
Trevor Smyth, Dr Gary Menary and Dr Marco Geron ${ }^{\text {a) }}$ \\ Queen's University Belfast \\ School of Mechanical and Aerospace Engineering \\ Ashby Building, Stranmillis Road, Belfast. UK \\ a)Corresponding author: m.geron@qub.ac.uk
}

\begin{abstract}
Impingement of a liquid jet in a polymer cavity has been modelled numerically in this study. Liquid supported stretch blow moulding is a nascent polymer forming process using liquid as the forming medium to produce plastic bottles. The process derives from the conventional stretch blow moulding process which uses compressed air to deform the preform. Heat transfer away from the preform greatly increases when a liquid instead of a gas is flowing over a solid; in the blow moulding process the temperature of the preform is tightly controlled to achieve optimum forming conditions. A model was developed with Computational Fluid Dynamics code ANSYS Fluent which allows the extent of heat transfer between the incoming liquid and the solid preform to be determined in the initial transient stage, where a liquid jet enters an air filled preform. With this data, an approximation of the extent of cooling through the preform wall can be determined.
\end{abstract}

\section{INTRODUCTION}

\section{Background and Motivation}

The consumer goods industry makes extensive use of plastic containers in order to package and distribute products, ranging from mineral water to laundry detergent. Plastic packaging for consumer goods is formed by a range of blow moulding processes, such as extrusion blow moulding and stretch blow moulding. The industry is substantial and growing, but operates with low margins; as a consequence there is a constant drive to increase efficiency and reduce the costs of producing these products.

Rigid plastic bottles are produced in the stretch blow molding (SBM) process by blowing compressed air into a preheated preform, which for Polyethylene Terephthalate (PET) is above its glass transition temperature $\left(\mathrm{T}_{\mathrm{g}}\right)$ ranging between $70-80^{\circ} \mathrm{C}$. The compressed air stretches the material radially, and a stretch rod acts to stretch the preform in the axial direction, thus providing the biaxial orientation necessary to enhance mechanical properties and gas barrier properties, important for such applications as carbonated beverages. A recent development in the industry has been Liquid Supported Stretch Blow Moulding (LSSBM), a derivative of SBM.

LSSBM has recently been developed $[1,2]$ for the forming of plastic containers; forming of the bottle shape and fill the cavity in a single stage, instead of two operations in SBM. By combining the two stages, capital expenditure can be reduced because less equipment is required. Producing and maintaining compressed air uses large quantities of energy in SBM, but no compressed air is required in LSSBM. The processing time can also potentially be reduced because forming and filling take place in a single operation. These factors combined can potentially reduce processing costs, which can be passed on to the consumer.

However, the presence of liquid as the forming medium introduces additional considerations; due to the increased density of the forming fluid versus air, gravity and inertial forces on the preform are no longer negligible, illustrated by Zimmer et al. [3] in a numerical and experimental mechanical study. Heat transfer is also potentially increased, for 
if convection is considered to be the primary mode of heat transfer at the inner surface of the preform, liquid flowing over a solid has a much greater heat transfer coefficient than air. There is therefore the potential that the forming window in LSSBM may be restricted, and the material behaviour altered, because as previously discussed, PET becomes formable above $\mathrm{T}_{\mathrm{g}}$. Overall, this research explores the feasibility of LSSBM with respect to the potential benefits and challenges outlined above. The heat transfer aspect has been chosen for consideration in this study. There are a number of thermal processes to consider; the convective heat transfer away from the hot preform, the conduction of heat through the wall thickness and the self-heating that occurs due to the stretching process.

\section{LSSBM and Liquid Jet Modelling}

The effect of preform temperature on the forming behavior of PET in SBM is known to be important and has been studied by a number of groups. Yang et al. [4] developed a non-isothermal finite element model of the process concluding that the final bottle properties, including orientation and crystallinity, were highly dependent on temperature and strain rate. Bordlval et al. [5] used numerical modelling techniques to determine an initial temperature profile to give uniform material distribution in the formed bottle. A heat transfer coefficient of $10 \mathrm{~W} / \mathrm{m}^{2} \mathrm{~K}$ for natural convection at a solid/air interface was applied across inner surface of the preform by Yang et al. [4] and Schmidt et al. [6]. However, because the heat transfer increases when liquid flows over the preform surface in LSSBM this heat transfer has the potential to have a much greater effect on the forming behavior of the bottle.

An alternative approach has been required to take into account the thermal influence on the LSSBM process. Zimmer \& Stommel [7] developed an axisymmetric heat transfer FE model solving the 1D heat conduction equation through the preform wall, at a single position along the wall, with the inner wall taking the temperature of the water, due to an assumed condition of infinitely fast heat transfer at the surface, and with no heat transfer occurring at the outer wall. Zimmer et al. [8] drew from that work in the development of a coupled thermomechanical model in which the heat transfer was modelled across the whole preform. It is suggested that the previous approach to LSSBM heat transfer could be improved upon by considering the dynamic effects of the liquid impinging on the internal preform surface, as opposed to a uniform condition across the entire surface.

Heat transfer due to liquid impingement on a flat surface has been modelled by Hosain et al. [9] and Tong [10], who also used 2D CFD methods but considered the interaction of two fluid phases using the Volume of Fluid (VoF) surface tracking technique. Impingement of a liquid jet on a concave surface has been studied by Xie et al. [11] who developed a 2D axisymmetric, single phase CFD model and tested a range of different diameter to depth ratios, and were able to obtain a correlative expression for average Nusselt number in the dimple cavity. The present study is concerned with the impingement of a liquid jet in a closed end cylindrical cavity, initially filled with air, for which the VoF method would be suitable and the impingement region is similar to that of a concave dimple.

The studies described above feature steady state flow problems, with flow into and out of the computational domains steady over time. The current problem is a transient case, the flow changing with time as the cavity is filled with the incoming liquid. In addition, using the approach of a single phase model, similar to that developed by Xie et al. [11] for the concave surface, the cavity is by definition initially filled, so cannot represent the filling of the air filled cavity with liquid, and the interaction between the two phases.

The objective of the study was to develop a CFD model of the initial stages of the LSSBM process, in which the preform remains static, which could be used to predict the evolution of temperature through the wall of the preform.

\section{CFD MODEL SETUP}

A numerical model of the impingement of a liquid jet in a closed end cylindrical cavity has been developed in commercial CFD software ANSYS Fluent. The problem can be simplified to be axisymmetric, greatly reducing the computational expense compared to a full 3D model. The behavior of the liquids in the cavity is highly dynamic and time dependent, so a transient calculation is necessary. The presence and interaction of the air and liquid in the cavity can be considered by using the Explicit VoF method. This method allows for the tracking and locating of the air-liquid interface, and evaluates the volume fraction of the phases throughout the domain. Alone, the VoF method is not a flow solving algorithm, so the Navier-Stokes equations must be solved in conjunction with the method, but only a single set is required for both fluids.

The main aim of this model was to predict the variation of temperature through the preform wall due to the flow of liquid across the internal surface, so it was necessary to include both the solid (preform) and fluid (air/liquid) in the model. Water has been chosen as the representative incoming liquid. In this initial stage the preform is assumed to 
remain static, with negligible mechanical deformation. Structural deformation does not occur so no fluid-solid mechanical interaction has been considered. Conjugate heat transfer has instead been modelled between solid and fluid domains. The Navier-Stokes (NS) equations are solved for the fluid, which includes energy, and in the preform only the heat transfer equation is solved, by means of conduction through the wall. The material properties for both fluid phases (water and air) and the Polyethylene Terephthalate (PET) are listed in TABLE 1. The flow is turbulent, with an approximate Reynolds number of $3 \times 10^{5}$ at entry to the preform, with turbulence being modelled considering a Reynolds Average approach for the NS equations. The closure of the NS equations has been achieved considering the Boussinesq approximation for the turbulent viscosity with a two equation Realizable k- $\varepsilon$ model being used.

TABLE 1 Material Properties

\begin{tabular}{llll}
\hline & Air & Liquid & PET \\
\hline Density $\left(\mathrm{kg} / \mathrm{m}^{3}\right)$ & 1.225 & 998 & 1330 \\
Specific heat capacity $(\mathrm{j} / \mathrm{kgK})$ & 1006 & 4182 & 1000 \\
Thermal conductivity $(\mathrm{W} / \mathrm{mK})$ & 0.024 & 0.6 & 0.24 \\
Viscosity $(\mathrm{kg} / \mathrm{ms})$ & $1.8 \times 10^{-5}$ & 0.001 & - \\
\hline
\end{tabular}

\section{Boundary and Initial Conditions}

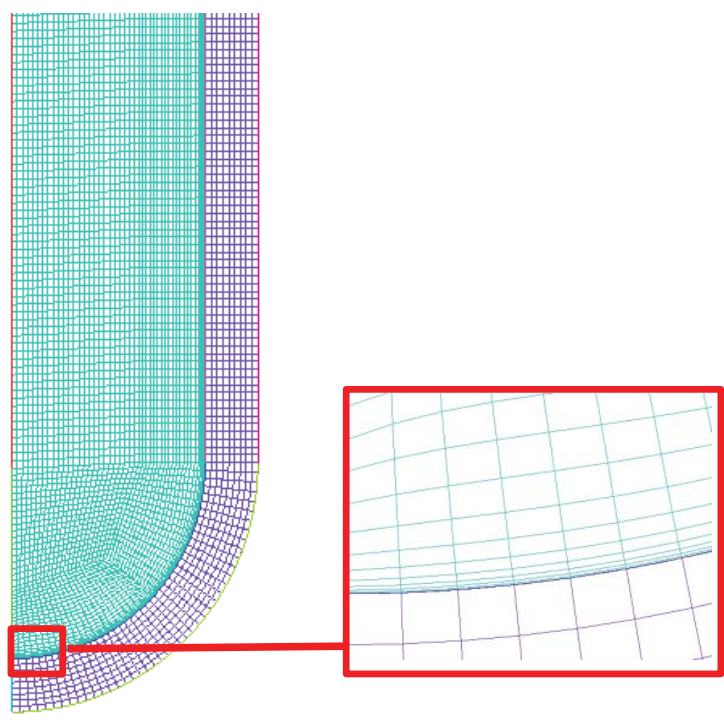

(a)

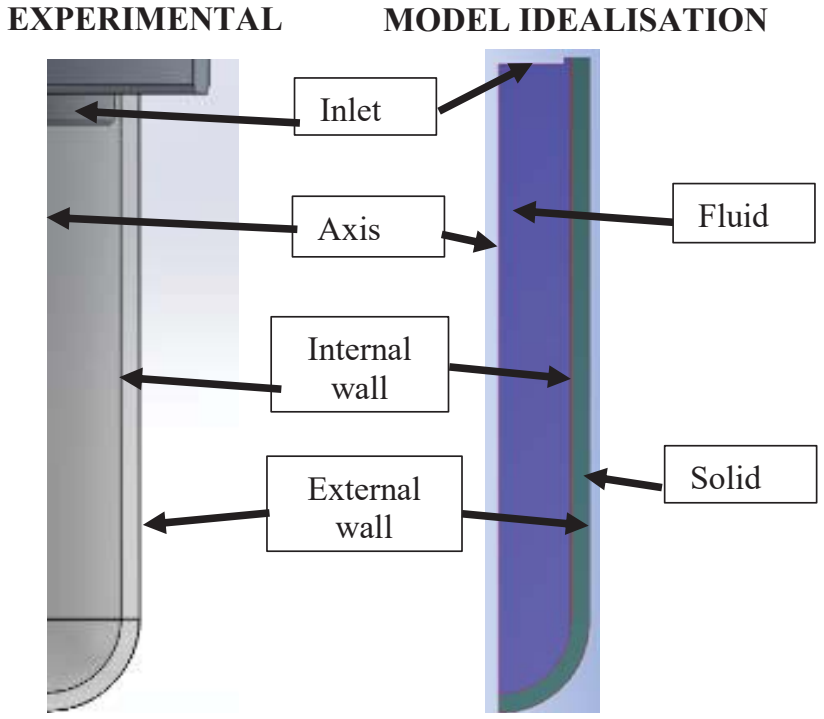

(b)

FIGURE 1 (a) The computational grid with bias towards the wall in the fluid domain (b) The experimental setup and model idealization for application of boundary conditions

The problem is considered to be axisymmetric, with a planar representation of the geometry about a central axis displayed in FIG. 1 (b). The liquid enters the initially air filled preform with a velocity of $15 \mathrm{~m} / \mathrm{s}$. At the inner surface of the preform, the boundary between the fluid and solid domains in the model, a non-slip wall condition is applied with a coupled thermal condition allowing for the modelling of the conjugate heat transfer between the solid and fluid. The external surface of the preform is assumed to be in contact with still air at room temperature (300K), represented by a wall condition with a constant convective heat transfer coefficient of $10 \mathrm{~W} / \mathrm{m}^{2} \mathrm{~K}$ for natural convection in air. For the initial conditions, the fluid is patched with the volume fraction of the liquid being set as 0 , representing the cavity containing air only. The patching technique is again used for the initial temperatures, with the fluid temperature initialized as $300 \mathrm{~K}$ and the preform at $373 \mathrm{~K}$.

The mesh was created using Ansys ICEM (FIG. 1 (a)), which allowed a conformal structured mesh to be created for the fluid domain. It is important that a high quality mesh is generated for the internal cavity wall; This is even more critical along the wall in order to properly capture the thermal and velocity boundary layers. The prediction of the heat transfer at the wall is of particular interest in this project; due to the complex nature of the multiphase flow 
and the high velocity and temperature gradients it has been chosen to resolve the boundary layer down to the viscous sublayer instead of modelling it through the use of common wall functions. This has been achieved in Fluent utilizing enhanced wall treatment in conjunction with the Realizable k- $\varepsilon$ turbulence model. In order that the sub layer can be resolved, it is desirable that the $\mathrm{Y}+$ value along the wall is approximately 1 , which will ensure the first cell height lies in the appropriate location through the boundary layer. Due to flow of the two separate phases, this value is considered applicable in the primary timeframe of interest, when the liquid flows across the surface.

\section{RESULTS AND DISCUSSION}

In a numerical problem grid convergence is determined by running the simulation with a number of successively refined grids, thus reducing the discretisation error. The error associated by using a particular grid can then be evaluated, considering the compromise between speed and accuracy, important in cases where the effect of different parameters are to be tested in different simulations. A convergence study was carried out for the preform with wall temperature as the variable of interest, comparing temperature through the thickness at $\mathrm{t}=0.015 \mathrm{~s}$ (FIG. 2 (a)).

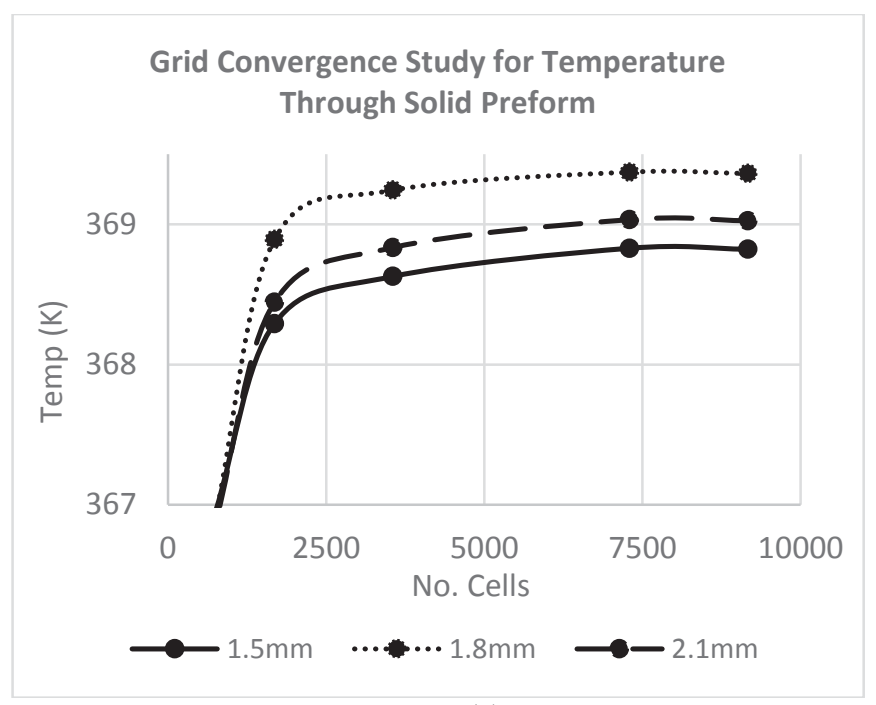

(a)

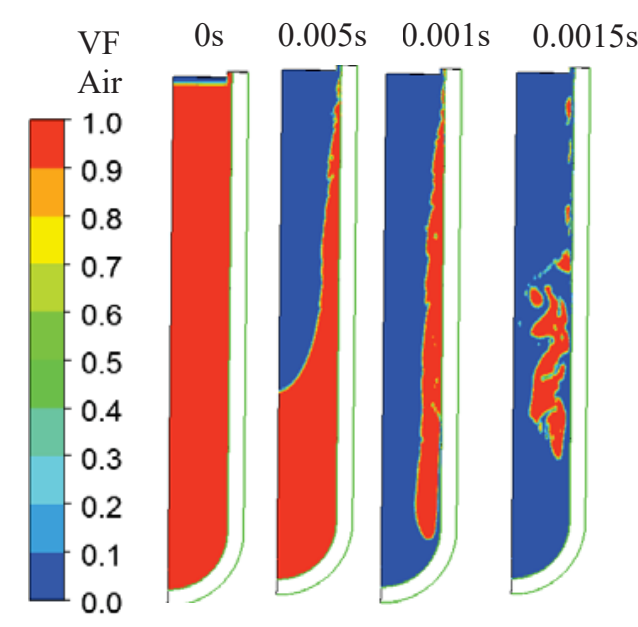

(b)

FIGURE 2 (a) Grid convergence at time $0.015 \mathrm{~s}$ (b) Progression of filling with time

In FIG. 2 (b) the evolution of the state of fluid composition in the preform is displayed. This illustrates the timescale of the filling and gives context to the temperature evolution data in FIG. 3 (a). Plotted on the contour is the volume fraction of air in the fluid domain. Notice at $\mathrm{t}=0 \mathrm{~s}$ the volume fraction of air is 1 throughout the domain, which corresponds to the initial idealization that only air be present in the cavity. As time progresses the influx of the liquid jet can be visualised where the volume fraction of air decreases to 0 , meaning the air is replaced with water in the cells. The initial impact of liquid on the wall of the preform occurs at approximately $\mathrm{t}=0.01 \mathrm{~s}$, and because of the similarity in diameter of the jet and the preform the filling is completed soon afterwards. It is to be noted that the air initially present in the cavity mixes with the liquid, as can be seen at $\mathrm{t}=0.015 \mathrm{~s}$, and is compressed. In the actual process it is possible that some of the air escapes through the inlet, as there is no other possible outlet due to the sealing of the cavity, but this has not been included in this initial iteration of the model. 


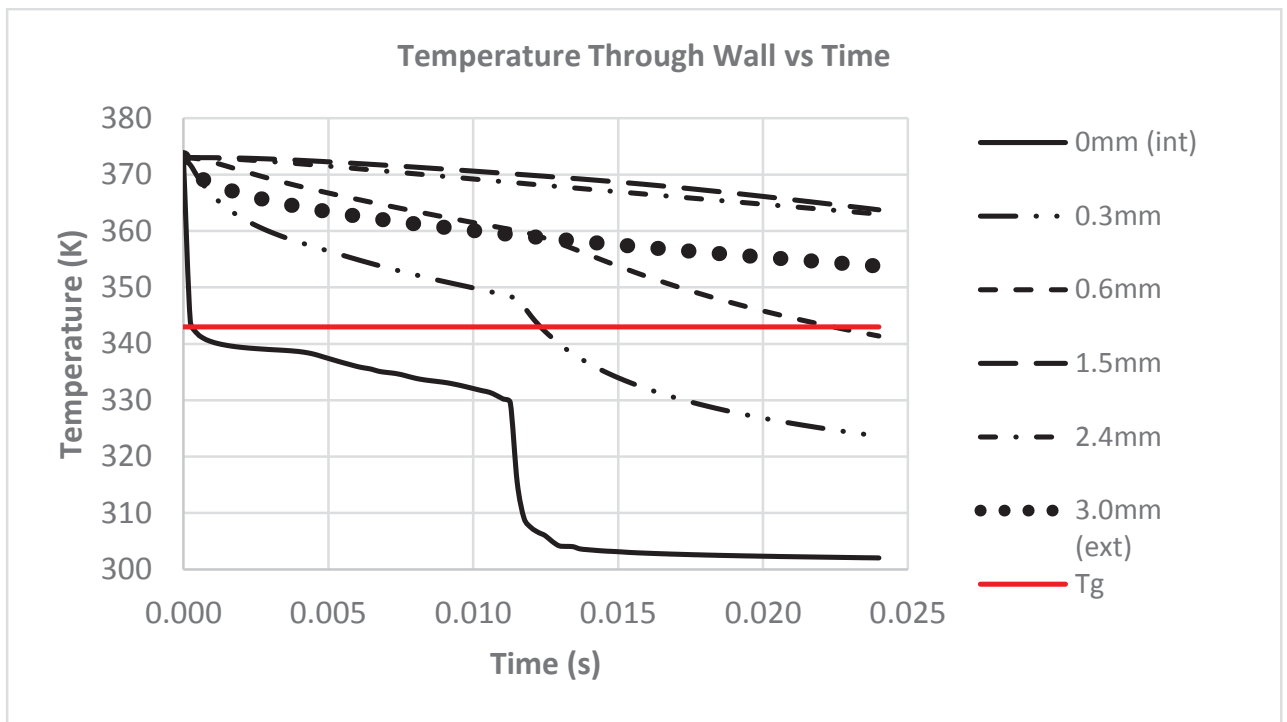

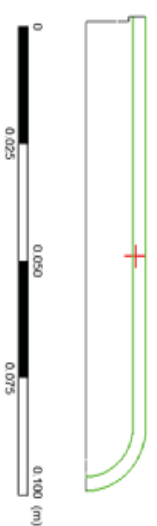

(b)

(a)

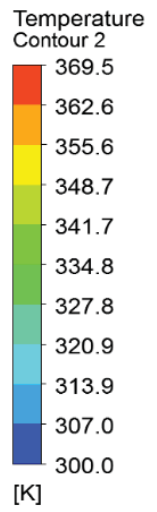

$[\mathrm{K}]$

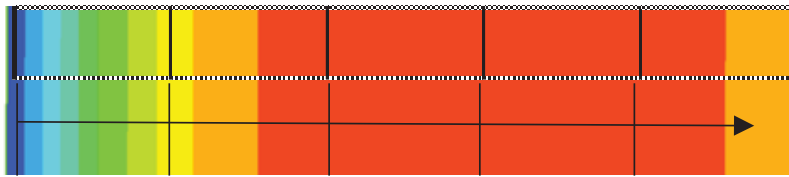

$1.2 \quad 1.8$

2.4 3

\section{Distance from internal wall (mm)}

(c)

FIGURE 3 (a) Evolution of temperature throughout the thickness (b) Location of sampling section on preform (c) Corresponding sampling section showing data points with temperature contour through section

The evolution of temperature throughout the wall is displayed in FIG. 3 (a) with a single section along the length of the preform being selected for analysis (b), with the points through the thickness displayed in (c) over a temperature contour at this section at $\mathrm{t}=0.015 \mathrm{~s}$, after the liquid has started flowing over the surface. In the plot of temperature against time (a), at $\mathrm{t}=0 \mathrm{~s}$ at the internal surface due to the initial contact with air the temperature drops quickly. Up until approximately $\mathrm{t}=0.012 \mathrm{~s}$, when the water comes into contact with the wall, the surface at this point remains in contact with air only, until contact with the water quickly reduces the temperature to that of the incoming water $(300 \mathrm{~K})$. The effect of the flow of liquid can be most clearly seen at $0.3 \mathrm{~mm}$ and $0.6 \mathrm{~mm}$, where the decrease in temperature can be seen to occur more rapidly than before water contact $(\mathrm{t}=0.012 \mathrm{~s})$. In the timescale of filling shown in (a) only the inner surface, $0.3 \mathrm{~mm}$ and $0.6 \mathrm{~mm}$ are predicted to fall below $\mathrm{T}_{\mathrm{g}}, 70^{\circ} \mathrm{C}$ or $343 \mathrm{~K}$. This temperature decrease is only during the short filling phase $(<0.02 \mathrm{~s})$ where preform wall thickness is at the initial maximum; according to measurements acquired by Bordival [5], Yang [4] and McEvoy et al. [12], the wall thickness potentially decreases towards $0.3 \mathrm{~mm}$ when forming is completed at approximately $0.2 \mathrm{~s}$ therefore the effect of liquid convection on the polymer is expected to increase as the preform expands. 


\section{CONCLUSIONS}

This numerical study considers the initial stage of the LSSBM process whereby a liquid jet enters and completely fills an initially air filled preform. A CFD model has been developed to predict the evolution of temperature through the preform, considering conjugate heat transfer between the fluid and solid domains. The interaction of the liquid and air phases is modelled using the multiphase VoF method. A grid convergence study has been conducted in order to satisfy an acceptable discretisation error tolerance, to provide a basis on which to conduct future parametric studies.

For this case in which a low temperature liquid was modelled $(300 \mathrm{~K})$ the results suggest that in the initial stage alone $20 \%$ of the material through the thickness is potentially cooled below its glass transition temperature. This distance through the wall will increase as a proportion of wall thickness as the thickness decreases due to preform expansion. For a jet inlet velocity of $15 \mathrm{~m} / \mathrm{s}$ the initial filling of the preform prior to pressure deformation is completed within $0.02 \mathrm{~s}$, approximately $10 \%$ of the total forming time of $0.2 \mathrm{~s}$. Despite this stage being of short duration in the overall process, the temperature evolution predicted indicates that it could be a significant factor during the total forming time.

In future work, the numerical model described in this study will be validated with respect to its ability to predict the preform temperature evolution. Subsequently, the objective will be to apply the same modelling approach to the next stage of the process, as the walls deform. With the development of a model which can predict the thermal evolution during the entire forming process, greater insight may be gained into the possible limitations introduced by the use of liquid as the forming medium, but also provide a method in which the process can be optimised.

\section{REFERENCES}

1. C. Desanaux, A. Contal, G. Denis G, U.S. Patent No. 7,473,388B2 (2009)

2. D. Andison, G.D. Lisch, D. Weissman, U.S. Patent No. 7,914,726B2 (2011)

3. J. Zimmer, G. Chauvin, M. Stommel, "Experimental Investigation and Numerical Simulation of Liquid Supported Stretch Blow Molding," in Polymer Engineering \& Science 55(4) (2014), pp. 933-44.

4. Z.J. Yang, E. Harkin-Jones, G.H. Menary, C.G. Armstrong, "A non-isothermal finite element model for injection stretch-blow molding of PET bottles with parametric studies," in Polymer Engineering \& Science 44(7) (2004), pp. 1379-90.

5. M. Bordival, F.M. Schmidt, Y.L. Maoult, V. Velay, "Optimization of preform temperature distribution for the stretch-blow molding of PET bottles: Infrared heating and blowing modeling," in Polymer Engineering \& Science 49(4) (2009), pp. 783-93.

6. F.M. Schmidt, J.F. Agassant, M. Bellet, "Experimental Study and Numerical Simulation of the Injection Stretch/Blow Molding Process," in Polymer Engineering \& Science 38(9) (1998) pp. 1399-412.

7. J. Zimmer and M. Stommel "Thermo-mechanical simulation of liquid-supported stretch blow molding," in PROCEEDINGS OF PPS-30: The 30th International Conference of the Polymer Processing Society, AIP Conference Proceedings (American Institute of Physics, Melville, NY, 2015)

8. J. Zimmer, D. Klein, M. Stommel, "Experimental and Numerical Analysis of Liquid-forming," in Key Engineering Materials 651-653 (2015) pp. 842-7.

9. M.L. Hosain, R. Bel Fdhila, A. Daneryd, "Heat transfer by liquid jets impinging on a hot flat surface," in Applied Energy 164 (2016) pp. 934-43.

10. A.Y. Tong, "Numerical Analysis of Hydrodynamics and Heat Transfer of a Free Surface Circular Jet Impinging Onto a Substrate," in ASME International Mechanical Engineering Congress Expo. (2007) pp. $1-8$.

11. Y. Xie, P. Li, J. Lan, D. Zhang, "Flow and Heat Transfer Characteristics of Single Jet Impinging on Dimpled Surface" in Journal of Heat Transfer 135(5) (2013)

12. J.P. McEvoy, C.G. Armstrong, R.J. Crawford, "Simulation of the stretch blow molding process of PET bottles," in Advanced Polymer Technology 17(4) (1998) pp.339-52. 